\title{
Public school districts learning to reduce pesticide risks to children
}

Done are the days when the school custodian

$\exists$ casually reached into the broom closet for a can of insecticide spray to kill a column of unwanted ants slurping up a spilled soda. "California's school districts are making more intelligent decisions about how they control pests," says Chris Geiger, a former research scientist at the California Department of Pesticide Regulation (DPR) who conducted a study on integrated pest management (IPM) in California public schools (see page 235).

Recent research supports the need for IPM in schools. In July, the Journal of the American Medical Association (JAMA) reported a significant increase in the number of acute illnesses associated with pesticide exposure among students and school employees nationwide (from 1998 through 2002). It recommended implementation of IPM practices and other measures to ensure reduced exposure to toxic chemicals in school settings.

California is among 17 states that have already passed legislation to address the issue. The Healthy Schools Act (HSA) of 2000 (AB 2260) calls upon public school districts throughout the state to identify IPM coordinators, maintain pesticide use records, notify parents and staff, and post before-and-after warnings of pesticide treatments. Although the law does not specifically require IPM practices, their use is encouraged through an educational effort spearheaded by DPR, which frequently turns to the UC Statewide Integrated Pest Management Program (UC IPM) for expertise.

\section{IPM training for schools}

Mary Louise Flint, UC IPM publications director, says UC materials have been incorporated in DPR's curriculum and Web site for district IPM coordinators. At a spring 2005 workshop for nearly 50 IPM coordinators in Butte County, the UC IPM program debuted an interactive train-the-trainer presentation for ant control, a prevalent pest problem in schools. After a demonstration, each participating school district received a DVD containing presentation materials, templates for handouts and activities to train their own employees.

"We discussed ant biology, food preferences and management strategies, emphasizing simple changes in everyday activities that can prevent ant invasions in the first place," Flint says. "Participants learned how to set up bait stations and practiced caulking on props to simulate sealing up cracks to keep ants out of school buildings."

UC IPM will be taking its train-the-trainer ef- forts to school districts again next year with programs on IPM for weeds and cockroaches, and general IPM principles. Along with Flint and several advisory committees of experts, UC IPM interactive learning developer Cheryl Reynolds and computer systems manager Joyce Strand have been involved in the development of these materials.

\section{Less-toxic practices}

Geiger's study, conducted in 2002, found that under the HSA California public schools are making progress toward an IPM approach, but he found differences between larger, urban schools and smaller, rural schools. In addition, preliminary results from a more recent survey conducted by DPR in 2004 show continued to progress. "The most important thing," Geiger says, "is that compliance has continued to increase."

Belinda Messenger, a DPR research scientist analyzing the 2004 data, says $64 \%$ of the districts surveyed are now in full compliance with the law, up from 50\% in 2002. "We found really high compliance (92\%) with use of warning signs before and after spraying," she says. "We also found $68 \%$ of the school districts have adopted an IPM program."

Messenger attributes the higher success rates to the ongoing workshops and pressure from parents. As of September 2005, about 39\% of the state's approximately 1,000 school districts had sent personnel to a workshop. A faculty lounge poster is also being developed to encourage teachers not to use sprays on their own.

Geiger described the hands-on training program as very effective, especially given its small budget. "It's quality over quantity," he says. "The university's role is absolutely essential. UC IPM is the only program of its kind that provides a central repository of peer-reviewed, science-based information." - John Stumbos
For more info, go to: www.schoolipm.info 